\title{
Thomas Kuhn's Philosophy of Language
}

\author{
Paulo Pirozelli ${ }^{1}$
}

\begin{abstract}
Thomas Kuhn is mostly known for his contributions to the philosophy of science. However, it was chiefly to investigations in philosophy of language that he dedicated the last part of his career. The aim of this paper is to present a systematic view of Kuhn's main ideas on this subject. I start by describing his theory of concept, in particular what he says about kind terms. Such terms, acquired in blocks that form contrast sets or "taxonomies," are learned through ostensible definitions. Next, I analyze Kuhn's concepts of "meaning" and "truth." Finally, I discuss a second type of kinds terms, not fully investigated by him, which is learned together with scientific laws.
\end{abstract}

Keywords: Thomas Kuhn. Philosophy of Language. Taxonomy. Meaning. Truth.

\section{INTRODUCTION}

Thomas Kuhn was always dissatisfied with what he considered were serious misinterpretations of his book The Structure of Scientific Revolutions (1962; henceforth, SSR). Motivated by that, he sought to develop some of his earlier ideas, especially regarding revolutionary change and incommensurability (1983; 1989; 1991a; 1992; 1993a; 1993b; 1999). In this attempt, Kuhn progressively moved his investigations to more language-related problems, even if ultimately concerned with matters in the philosophy of science.

One of the problems in adequately comprehending this philosophy of language, though, is its fragmented character. Kuhn's views on the matter were exposed in a series of articles that dealt with specific questions, such as the theory-choice problem, the structure of revolutionary changes or the nature of paradigms. The link among these various issues, however, was not always straightforward.

${ }^{1}$ Doutorado em Filosofia pela Universidade de São Paulo, São Paulo, São Paulo - Brasil.

Dhttps://orcid.org/0000-0002-4714-287X E-mail: paulopirozelli@gmail.com

http://doi.org/10.1590/0101-3173.2020.v43esp.25.p345

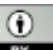

This is an open-access article distributed under the terms of the Creative Commons Attribution License. 
This paper intends to present a systematic view of Kuhn's main ideas on the philosophy of language. I start by describing his theory of concept, in particular what he says about kind terms. These concepts are learned through ostensible definitions, and need to be acquired simultaneously in a contrast set, forming what Kuhn calls "taxonomy." Following that, I analyze his conceptions of "meaning" and "truth." Finally, I discuss a second type of kind term, not fully investigated by him, which is learned simultaneously with scientific laws.

This article confines itself to examining the foundations of Kuhn's philosophy of language - a broad set of topics that includes "kind terms," "taxonomies," and "ostensible definitions." Their implication to Kuhn's philosophy of science will not be explored here, however. ${ }^{2}$ Issues such as the difference between translation and interpretation, the correspondence theory of truth, and the incommensurability thesis will not be directly approached. The reason for this methodological cut is the existence of a vast bibliography on these subjects, which is not the case with Kuhn's philosophy of language.

Two main reasons make a study of Kuhn's philosophy of language worthwhile. First, it helps us understand how some of his most important theses were transformed after his linguistic turn in the 1980s ("incommensurability" above all). Moreover, Kuhn's ideas on the nature of language can still bring invaluable contributions to the current debates in philosophy, especially as to the problems of realism and the meaning of theoretical terms.

\section{LEARNING}

A study of Kuhn's philosophy of language should start by analyzing the nature of learning, since he maintains that the way a lexicon is acquired is "a source of clues to what the individual's possession of a lexicon entails" (KUHN, 1989, p. 66, n. 11; see also 1962, ch. 5). That does not imply that the functioning of language necessarily depends on a specific form of teaching, nor that alternative modes of learning capable of ever producing the same results could not exist (KUHN, 1989, p. 66, n. 11; 1974, p. 312-13). In principle, words could be learned in a way different from that described by Kuhn. Nevertheless, the fact that determinate processes of learning are

\footnotetext{
2 The division between the foundational, more theoretical parts of Kuhn's theory of language, and his more applied concepts and theses is relatively arbitrary. Despite that, I believe this distinction allows us to circumscribe an interesting set of topics related to philosophy of language in Kuhn's writings.
} 
usually linked to certain linguistic functionings allows us to treat them as useful indicators of how language works. ${ }^{3}$ Moreover, what interests Kuhn are general traits of learning, not specific circumstances related to particular teaching techniques.

\subsection{Ostensible Teaching}

How does a person understand the meaning of a word? Retreating to a more general problem of word learning, not limited to scientific concepts, may sound too ambitious. But as Kuhn's examples make clear, the way scientific concepts are learned is similar to that of ordinary language concepts (KUHN, 1974, p. 313; NERSESSIAN, 2003, p. 179; BARKER et al., 2003, p. 215).

For Kuhn, learning begins with the ostension of similar objects (KUHN, 1974, p. 309; 1989, p. 66). This is the basic teaching process of almost every word we use. According to Baker \& Hacker (2009, p. 85), an ostensive definition consists of three main elements: i) a deictic gesture - that is, an action that directs the attention of the listener (pointing the finger, indicating with the head, etc.); ii) an object of some kind (a physical object, a smell, etc.); and iii) a linguistic formula, indicating that an ostensive definition is being provided.

This last aspect points to a differentiation made by Kuhn between "ostension" and "ostensive." In the first case, "nothing but the exhibit of a word's referent is needed to learn or to define it" (KUHN, 1989, p. 67, n.13). In the second, the process involves some kind of display of referents, but may be supplemented by other elements as linguistic formulas. Kuhn deals exclusively with the latter. In fact, for him, ostensive presentations can even dismiss actual, concrete exhibitions. Instead, they can be discursively constructed visualizations, "describing these potential examples in the vocabulary antecedently available" (KUHN, 1993a, p. 247; 1989, p. 66). In this sense, he departs slightly from the Wittgensteinian characterization of ostensive definition made by Baker \& Hacker (2009), in dispensing with the deictic gesture. This does not imply to reject, as a whole, the idea of ostensive definitions. The use of imagined examples is not the same as teaching through definitions - i.e., conveying necessary and sufficient rules for the use of a word. It only means that certain linguistic tools allow the student to visualize the appropriate example, either by relating it to a similar one she already

3 Wittgenstein (2009, \$77) makes a similar argument. 
knows or by helping her to imagine a situation that could hardly be materially constructed.

The learning of concepts has an essentially normative character. The ostensive definition conveys the rules that govern the use of a given expression, thus providing the correct pattern of use accepted by the community. The examples presented are not intended to describe facts and generalizations about the actual linguistic practice, but to convey the rules of employment of the term.

It is possible to add other aspects to Baker \& Hacker's (2009) definition. Some of them are relatively obvious, such as the need that perceptual and cognitive faculties be in order, or that the person who is teaching masters the use of the term being taught. Another prerequisite is that the learner knows that the instructor is giving an ostensive definition, and what exactly is being defined. This is only possible when a person has reached a certain level of linguistic maturity (KUHN, 1989, p. 66), possessing a knowledge of the language that allows her to understand the act of the instructor as an ostension. In Wittgenstein's $(2009$, \$30) words, “[...] an ostensive definition explains the use - the meaning - of a word if the role the word is supposed to play in the language is already clear".

Without this prior understanding of the ostensive act as such, the mere fact of pointing is of no use. For the pupil who is unable to understand what type of object is being defined - to which general class it belongs the indicative gesture made by the instructor is ineffective. Using one of Kuhn's most common examples, it is only by virtue of the child knowing that "ducks," "geese" and "swans" are all birds, that the father's act of pointing out animals and pronouncing the phrase, "That is a goose, this another a swan, that a duck," produces the desired effect (KUHN, 1974, p. 309ff.). In addition, learning may also require sometimes the possession of specific technical vocabulary (KUHN, 1993a, p. 248).

\section{2 ОвJECTS}

Does the ostensive act need to be reiterated? Surely, a personal element is always involved in the amount of identifications required for understanding a particular term. Different people may need different numbers of ostensions, and the same person may need a different amount of them to learn apparently 
similar concepts. The variability is due to the context of teaching, as much as to cognitive capacities and personal background.

Another - and more determining - element for the number of ostensible acts needed to learn a term, has to do with the nature of the object explained. Kuhn distinguishes two types of things that can be presented by ostensible definitions. The first type concerns proper names. In this type of ostension, what is learned is that a specific name designates a certain person, animal, or object. The second type of ostension, in turn, serves to explain the meaning of a kind term. ${ }^{4}$ In each case, according to Kuhn, ostension operates differently: while for proper names a single act of ostension may be enough to establish the reference, kind terms demand a number of acts of ostension (KUHN, 1979, p. 200; 1989, p. 67; 1993a, p. 230).

The reason for this will be made clear when discussing the apprehension of similarity relations. For now, what is important to note is that Kuhn is only interested in the second type of ostensive definition, the one that allows for understanding a concept corresponding to a "natural family" (KUHN, 1962, p. 45) or "natural kind" (KUHN, 1989, p. 82). By this expression, Kuhn (1970a, p. 285) understands

[...] an observed cluster of like objects, sufficiently important and sufficiently discrete to command a generic name. More precisely, [...] a natural family is a class whose members resemble each other more closely than they resemble the members of other natural families.

Kuhn's use of the expression "natural families" is not limited to kinds of the physical world. Instead, he is concerned with a characterization of kind terms in general, including not only "kinds of physical object (e.g., elements, fields, and forces), but also kinds of furniture, of government, of personality, and so on" (KUHN, 1993a, p. 229; see also 1991a, p. 92). ${ }^{5}$

\footnotetext{
${ }^{4}$ One of the flaws of the causal theory of reference is, for Kuhn, its inability to distinguish these two classes of objects (1989). See (KUUKKANEN, 2010) for an exposition of Kuhn's argument, and (BIRD, 2000, p. 179ff.) for a criticism of it.

5 Two other observations on the use of the expression "natural families." First, even though Kuhn usually refers to lexicons, terms, and sentences - that is, linguistic categories - he claims to be concerned with "conceptual or intensional categories in a more general way, e.g., with those that may be reasonably attributed to animals or to the perceptual system" (1989, p. 60, n. 2; also 1991a, p. 94; 1993a, p. 229). Concepts for kinds, according to him, do not even need to have names, although they tend to in populations endowed with language. The second observation regarding natural families is that they should not be understood as being tied to a realistic attitude - "natural" here refers to the
} 


\subsection{Similarities}

The last element involved in ostensive definitions is the relation of similarity. As said before, ostensive teaching serves to transmit the knowledge of certain natural families. But how is it possible that someone learns the meaning of the term for a whole class only by being presented a few instances of it - knowledge that allows the classification of objects not yet seen?

A first attempt at a solution comes from an essentialist conception of meaning. According to this alternative, the ostensive definitions would serve as an instrument to grasp, either consciously or unconsciously, a certain set of attributes common to all members of a class (KUHN, 1974, p. 302, n.11; 1962 , p. 45). Kuhn enumerates various pieces of evidence that make the existence, and especially the employment, of such general properties doubtful. First, few of these rules are found by scientists in textbooks or throughout their education and professionalization. Besides that, they are usually incapable of articulating them. Another piece of evidence is that students who claim to have understood a theoretical explanation are frequently unable to relate the theory to particular applications. Finally, solutions proposed by scientists throughout history tend to be modeled on previous solutions and not on explicit rules (KUHN, 1974, p. 305-06; HOYNINGEN-HUENE, 1993, p. 106).

Kuhn contrasts this essentialist conception of meaning with Wittgenstein's notion of family resemblance (WITTGENSTEIN, 2009, $\$ 67)$. Family resemblance denies that objects belonging to a class need to share any set of characteristics, "simultaneously applicable to all members of the class and to them alone" (KUHN, 1962, p. 45), that are known to the speakers and used by them as rules for the use of the concept. Instead, Kuhn defends that a concept may be "constituted by a network of overlapping and crisscross resemblances" (KUHN, 1962, p. 45), without any "loss of functional precision results" (KUHN, 1979, p. 201).

Thus, a kind term can be understood through an ostensive definition if the person perceives the underlying similarity between its instances. ${ }^{6}$ It is the latter, and not some hidden property, what gives unity to the class. But, there is a problem: at the limit, any object is similar to any other object in some sense. "Similarity," Searle explains, "is a vacuous predicate: any two things

immediacy of similarity relations (HOYNINGEN-HUENE, 1993, p. 72, n. 31). I will come back to this anti-realist conception of natural kinds after discussing contrast sets.

${ }^{6}$ Here, I follow closely Andersen (2000), in her analysis of Kuhn's use of the concept of family resemblance. 
are similar in some respect or other" (KUHN, 1979, p. 96). If that is the case, how is it possible to determine what belongs to a class or not - since any object could be similar to some instance of that class in a certain way? That is precisely the problem known in the literature as the "open texture of concepts," or "vagueness of meaning" (KUHN, 1974, p. 316, n. 21).

A few possible solutions to the difficulty could be considered: i) postulating that all the instances of the class share an unknown common property; ii) assuming classifications are completely arbitrary; or, iii) concluding that our most familiar concepts do not really work, for every object is an instance of every concept. The three options are, in other words, essentialism, nominalism, and skepticism. Although Kuhn does not argue directly against any of these theses, he defends a different solution. For him, the infinite progress of the series can be brought to an end by the presence of other classes. To see how this could happen, consider the existence of two natural families, $K$ and $J$, both operating through family resemblances; with two instances each, $k_{1}, k_{2}$, and $j_{1}, j_{2}$; and with properties designated by uppercase letters:

$\begin{array}{lllllllll}k_{1} & \mathrm{~A} & \mathrm{~B} & \mathrm{C} & \mathrm{D} & & & & \\ k_{2} & \mathrm{~B} & \mathrm{C} & \mathrm{D} & & \mathrm{F} & & \\ & & & \ldots & & & & \\ j_{1} & & & & \mathrm{E} & \mathrm{F} & \mathrm{G} & \\ j_{2} & & & & \mathrm{E} & & \mathrm{G} & \mathrm{H}\end{array}$

What would happen if we tried to add an instance $k_{3}$, with characteristics $\mathrm{B}, \mathrm{E}$ and $\mathrm{G}$, to class $K$ ? That would not work, since despite sharing the characteristic $\mathrm{B}$ with some instances of $K, k_{3}$ is much more similar to the elements of $J$. The extent of $K$, thus, is bounded by that of $J$, and viceversa (ANDERSEN, 2000, p. 319).

However, the presence of contrast sets is only capable of delimiting the expansion of a concept by a certain set of characteristics. For instance, while the expansion of instances of $K$ in the last example was limited by the elements of $J$, nothing would prevent $K$ from continuing to expand through features different from those present in the members of the latter class, as above: 


$\begin{array}{lllll}e_{1} & \mathrm{C} & \mathrm{D} & \mathrm{R} & \\ e_{2} & & \mathrm{D} & \mathrm{R} & \mathrm{Y}\end{array}$

The answer to this difficulty lies in assuming the existence of contrast sets at higher levels. Let us call $\mathbf{X}$ the concept that encompasses $A$ and $B$ (as "ducks" and "geese" form part of the "water bird" concept). Being a concept learned through family resemblance, $\mathbf{X}$ is itself part of a larger contrast set. Suppose $\mathbf{Y}$ is a member of it. As $A$ and $B$ are mutually limited, so too are $\mathbf{Y}$ and $\mathbf{X}$. Thus, there would be certain typical features of objects belonging to $\mathbf{Y}$, as, for example, C, D, and R, which would not appear in objects of $\mathbf{X}$. Just as the contrast sets are limited by each other, the expansion of the concepts encompassing them would also be halted by the existence of a higher-level contrast set (ANDERSEN, 2000, p. 323). ${ }^{7}$

According to Kuhn (1974), the identity of a concept governed by family resemblance rests on the existence of mutually limiting. In other words, a kind term can only be established together with a group of other contrasting terms. For this reason, the teaching of a kind term must always include the presentation of similarities (which objects are similar and belong to the same class), as much as dissimilarities (which objects are not similar to them and belong to contrasting concepts) (KUHN, 1979, p. 200; 1981, p. 30-31; HOYNINGEN-HUENE, 1993, p. 72). Kind terms need to be acquired in a group, and they must consequently constitute, within a certain locality of language, a hierarchic and holistic organization (KUHN, 1983, p. 51-52; BARKER et al., 2003, p. 217). This set of contrasting concepts, which form a "multidimensional lexical network" (KUHN, 1983, p. 55), are also referred as a "taxonomy" (KUHN, 1981). ${ }^{8}$

Unfortunately, the presentation of contrast sets does not eliminate all the theoretical difficulties. Another problem arises when thinking about objects located at the threshold of the contrasting concepts: for Kuhn, the existence of intermediate objects in between the natural families would undermine the possibility of family resemblance operating. In that situation, anomalies would

\footnotetext{
7 Hacking (1993, p. 286) seems to believe that at the uppermost level, there is just a single concept, a head, which is not subsumed by any other concept. Khalidi (1998, p. 36), on the contrary, treats the taxonomy as ending with a number of different heads. Kuhn does not say anything about this specific point.

${ }^{8}$ Kuhn uses the expressions "taxonomy/lexicon/lexical taxonomy" and "taxonomic term/lexical term" indistinctly.
} 
arise - objects that do not fit into any of the existing sets, or that fit into more than one - collapsing that part of the language. For these concepts to work properly there must be a gap between instances of natural families. The objects falling into a class must keep some distance from objects that are instances of contrasting concepts - they cannot overlap or blend (KUHN, 1962, p. 4546; 1974, p. 312; ANDERSEN, 2000, p. 322). ${ }^{9}$ Hence, for Kuhn, one of the conditions for family resemblance to function is the existence of an "empty perceptual space between the families to be discriminated" (KUHN, 1970c, p. 196, n. 14). Only when these conditions are respected - when there is not "a perceived continuum" (KUHN, 1970c, p. 196, n. 14) among classes - can family resemblance concepts function (dismissing necessary and sufficient rules).

The condition that contrasting classes be separated may suggest that Kuhn is presupposing a metaphysical cleavage among objects pertaining to different concepts. That is not the case, though. There is no need to assume "that there is only one, true categorization based on similarity and dissimilarity in specific respects which can be read off the world itself" (ANDERSEN, 2000 , p. 320), or that the gaps are anterior to human perception and independent of it. Instead, the only requirement is that classes be separated into a perceptual universe "after neural processing" (KUHN, 1970c, p. 196, n.14). Indeed, several different categorizations are possible for Kuhn. The reason is that similarities do not exist by themselves. Instead, they are created when certain objects are juxtaposed and the person is able to establish a criterion for grouping them (KUHN, 1979, p. 197). Hence, categorizations have both a subjective and an objective side (HOYNINGEN-HUENE, 1993, p. 74-76; see also 1979; 1962, p. 4-5). This is, in fact, what makes scientific revolutions possible. ${ }^{10}$

One last question can be raised now. Insofar as a person can separate the referents of contrasting concepts, would not she be establishing, at least unconsciously, some sort of rule for their identification? Kuhn's answer is subtle. While denying that kind terms, with rare exceptions, are commanded

\footnotetext{
${ }^{9}$ At this point, Kuhn claims to be taking a step further than Wittgenstein, by stipulating the "sort of world necessary to support the naming procedure he outlines" (1962, p. 45).

${ }^{10}$ This does not imply that any categorization is possible and "scientists may choose any theory they like so long as they agree in their choice and thereafter enforce it" (KUHN, 1970b, p. 263). According to Kuhn (1962, p. 4), "observation and experience can and must drastically restrict the range of admissible scientific belief, else there would be no science". His point is solely to emphasize that the world does not impose a single categorization of nature. There is always "an apparently arbitrary element, compounded of personal and historical accident" (KUHN, 1962, p. 4) involved in the classification of objects. For an explanation of this in terms of stimulus and sensation, see $1970 \mathrm{c}$, sec. 4 .
} 
by definitions, he assumes that people emerge from learning "with an acquired list of features salient to the required similarity relation" (KUHN, 1981, p. 31). According to him, the person who understands a family resemblance concept comes up with a list of criteria for picking up the referents. That list could involve involuntary neuronal reprogramming, in which the person's perception would become more sensitive to certain traits of the objects, and explicit generalizations (KUHN, 1974; 1983, p. 50, n. 22).

This may sound as an indirect way of saying that similarity is simply a pedagogical instrument for conveying definitions that later are unconsciously grasped by the subject. But that is not what Kuhn claims. The point is that the criteria used to select the referents of terms do not provide a set of necessary and sufficient conditions, accepted by the community, that establish their meaning. ${ }^{11}$ These criteria are just subjective tools used to discriminate the extension of concepts, which actually presuppose an extension that, at least for paradigmatic cases, has already been settled by the community. The similarity presented to the individual is thus "logically and psychologically prior to any of the numerous criteria by which that same identification of similarity might have been made" (KUHN, 1974, p. 306).

In other words, what makes an object belong to a class is its similarity with paradigmatic examples accepted by the community, not an agreement with a definition (especially one that is unknown). Generalizations can be, and usually are, employed in the processes of understanding and learning, but they do not establish the limits of the classes (KUHN, 1974, p. 309ff.). This is done by the similarity relation accepted by the community. This is why Kuhn can assert that the relation of similarity "does not depend on a prior answer to the question, similar with respect to what" (KUHN, 1974, p. 306; 1993b, p. xiii). ${ }^{12}$

Consequently, it does not matter (most of the time) what criteria are actually used by the language users, as long as they can select the appropriate referents of the contrast set. In principle, "one may legitimately make use of anything one knows or believes about those referents" (KUHN, 1983, p. 50), and in the limit speakers could "share a concept without sharing a single belief

\footnotetext{
${ }^{11}$ Kuhn states that if one wants to view criteria as definitions, they must be seen as definitions that do not need to be shared by other members of the community (1989, p. 67).

${ }^{12}$ There is extensive literature showing the proximity of Kuhn's ideas on the nature and functioning of concepts to certain contemporary approaches in cognitive science. For three good introductions, see NERSESSIAN, 2003; BARKER et al., 2003; NICKLES, 2003.
} 
about the feature or features of the objects or situations to which" it can be applied (KUHN, 1991b, p. 219).

\section{TAXONOMY}

Later, Kuhn (1981) further explores the idea that concepts for kinds are learned together, forming a "taxonomy." This is the case of sets of words like solid-liquid-gaseous (KUHN, 1993a), or planet-meteor-star (KUHN, 1991b). These taxonomic terms share four main characteristics. First, they have grammatical properties that identify them as terms for classes, as for example, that of admitting the use of the indefinite article (KUHN, 1991a, p. 92; 1993a, p. 230). Secondly, their application is essentially unrestricted, not being limited by anything extrinsic (KUHN, 1993a, p. 249). ${ }^{13}$

Third, kind terms are projectable - "to know any kind term at all is to know some generalizations satisfied by its referents and to be equipped to look for others" (KUHN, 1993a, p. 230). As we saw, these generalizations serve to discriminate the instances of contrasting concepts. They can be taught by a more experienced member of the community or can be created by the person who learns a term herself. In any case, projectability means that the knowledge of a kind term is inseparable from some implicit or explicit knowledge about its nature and behavior (KUHN, 1983, p. 211). ${ }^{14}$

In that sense, learning a concept implies learning simultaneously something about the nature it describes. Through ostensive definition, not only are concepts acquired, but also information about the world they apply to $(\mathrm{KUHN}, 1993 \mathrm{a}$, p. $230 ; 1999$, p. 34). In other words, there are not two distinct types of distinct knowledge - the knowledge of words and the knowledge of nature are actually just "two faces of the single coinage that a language provides" (KUHN, 1981, p. 31).

An immediate consequence of a term's projectability is that it can be used to make predictions, since knowing what a term means is knowing some

\footnotetext{
${ }^{13}$ Kuhn does not explain why "to discover that the scope of a kind concept is limited by something extrinsic, something other than its meaning, is to discover that it never had any proper applications at all" (1993a, p. 249). Perhaps, we can presume it is because these terms would then violate the nooverlap principle (which will be explained ahead), generating conflicting generalizations in certain domains.

${ }^{14}$ On the relation of "projectibility" and the incommensurability thesis, see (KUHN, 1993a, p. 23133; HACKING, 1993, p. 295-27).
} 
characteristics about them. Thus, a person who understands what a "bird" is, must necessarily be capable of making inferences like, "If $X$ is a bird, then it has feathers."

The last characteristic of kind terms is that they obey the so-called "no-overlap principle" (KUHN, 1993a). As we have seen, it is a fundamental prerequisite that the extension of a concept be limited by its contrast sets. Two consequences follow from this: first, more obviously, that an object cannot belong to different concepts in the same contrast set; and second, that any object that is an instance of a kind $K$ can only pertain to kinds that are hierarchically above or below $K$. As Kuhn says, "no two kinds, no two terms with the kind label, may overlap in their referents unless they are related as species to genus" (KUHN, 1991a, p. 92). In other words, two concepts can share the same referents just in case one of them wholly subsumes the other. ${ }^{15}$ "Max," for instance, cannot be a dog and an eagle at the same time. But by being a dog, he is necessarily a mammal (see HACKING, 1993, for a formal presentation of this last point).

If any of these requirements were violated, the same object would be subject to conflicting generalizations (KUHN, 1993a, p. 232), and therefore, to incompatible inferences. For example, if $X$ were both a bird and a fish, or a bird and a reptile, or a bird and a German shepherd, it would be possible to say that $X$ has and has not wings (in the first case, because it is a bird, and in the second, because it is a fish/reptile/German shepherd). Language, thus, would become inconsistent.

It is important to notice, though, that the no-overlap principle is limited to classes belonging to the same set of contrasts. This means that an object may simultaneously belong to more than one class in two sorts of situations, if these classes are part of different contrast sets. "Bertrand Russell," for instance, can be a male and philosopher. Since these concepts are not part of the same contrast set, they are not mutually exclusive. ${ }^{16}$

\footnotetext{
${ }^{15}$ Instead of "overlapping," Khalidi (1998, p. 36) prefers to speak of "crosscutting," "since superordinate categories that wholly include others might be said to overlap with their subordinate categories but not to crosscut them." I believe Kuhn would agree with that.

${ }^{16}$ McDonough's (2003, p. 43) criticism of Kuhn's taxonomic kinds misses this point. By supposing that the non-overlap principle is absolute, he concludes that most of scientific terms do not fit Kuhn's model, constituting "not a hierarchic tree, but a series of overlapping patches." Kuhn, however, makes it clear that the non-overlap principle is relative to contrast sets (1993a, p. 232). His theory is what Khalidi (1998, p. 35) considers a weak hierarchic thesis: "categories cannot crosscut only within a single theory, as opposed to across the entirety of science or our entire collection of theories."
} 


\section{MeANing}

$S S R$ presents a series of examples of change in meaning along scientific revolutions, but the exact nature of this phenomenon is never explained. ${ }^{17}$ Kuhn's approach to the philosophy of language, especially since the 1980s, reflects a growing concern with this problem. "With respect to kind terms," he assures, "aspects of a theory of meaning remain at the heart of my position" (KUHN, 1993a, p. 229; see Kuhn (1983, p. 36), in which Kuhn still avoids the question of meaning).

Kuhn has no "meaning theory per se" (KUUKKANEN, 2008, p. 78), but his discussions on the subject, as well as his claims about scientific revolutions, allow us to infer some core features of it. Let us start by discussing what "meaning" is not for Kuhn. In the first place, "meaning" is not for him synonymous with "sense" or "intensionality" - the way in which the referents of words are determined. Speakers can "use different criteria in picking out the referents of its terms" (KUHN, 1983, p. 50), and a person may even come to modify the criteria used to select the referents of a term after new experiences. As long as people refer to the same objects, that means they are using the same concept, despite the expectations they connect to it.

"Meaning" is not "extensionality" either - the set of objects referred by a term (KUHN, 1983, p. 50). ${ }^{18}$ Knowing the meaning of a term is not only picking up the right referents for it. It also depends on grasping the relations of dissimilarity maintained with instances of other terms in the language (more specifically, with those that constitute its contrast set), a necessary consequence of the holistic structure of taxonomic terms. In this sense, Kuhn says, "something from the realm of meanings, intensionalities, concepts must be invoked as well” (KUHN, 1983, p. 47).

So, "meaning" is not limited neither to "sense" nor "reference," neither to intensionality nor extensionality (KUHN, 1981; 1983). Instead, it involves

\footnotetext{
${ }^{17}$ In one of the first reviews of SSR, Shapere (1964) criticized Kuhn for basing many of the book's theses on a concept of "meaning" and "meaning change" Kuhn himself had not developed.

${ }^{18}$ When talking about the reference of a scientific kind, it is important to have in mind that Kuhn does not assume a realist position. That would be extremely problematic, since different theories presuppose (and also deny) the existence of different sorts of objects. Kuhn, on the contrary, insists that the reference of a taxonomic term is not independent of human classification. Contrary to Hacking (1982), he holds a notion of "kind" that "will populate the world as well as divide up a preexisting population" (1993a, p. 229). Hence, the "extension" or "reference" of a taxonomic term may be understood as simply the types of situations or events that are considered as indicative of the presence of objects of that kind for users of a certain taxonomy.
} 
both aspects. Each term, Kuhn explains, is "a node in a multidimensional lexical network" (KUHN, 1983, p. 52), linked to other words as well as to nature. The meaning of a term is simultaneously connected to its referents and to other terms in the lexicon (KUHN, 1983, p. 55). Consequently, the meaning of a term cannot be established alone, but must be apprehended simultaneously with the rest of the network. None of the terms, Kuhn asserts, "has an independently specifiable meaning" (KUHN, 1983, p. 55; 1989, p. 62-63). "With occasional exceptions," he says, "terms do not individually have meanings at all” (KUHN, 1989, p. 77, n.25).

Kuhn (1989) takes a fundamental step towards a more developed conception of "meaning," when he incorporates a Wittgensteinian approach, discarding the old Fregean theoretical framework. Now the notion of meaning is seen as that of proper use:

[...] knowing what a word means is knowing how to use it for communication with other members of the language community within which it is current (KUHN, 1989, p. 62).

To say that knowing the meaning of a word is the same as being able to use it properly is not to reduce the knowledge of a word to the ability of operating with its syntactic rules. Adequate use involves a number of other aspects besides syntactic manipulation, such as: being able to properly select the referents that pertain to the extension of the concept; knowing how to distinguish these instances from objects that look similar but belong to contrast sets; and knowing what kind of propositions can be formulated with it and in which contexts (at least, a few of them).

It is important to clarify an aspect in relation to the Wittgensteinian conception of meaning as use. It does not merely assert that if someone knows the meaning of a word, then the person is able to use it correctly - a reasonable but trivial conclusion. Instead, Wittgenstein argues that the use of a word is not a consequence of it being understood, but is actually the criterion of comprehension. What determines knowledge is simply the correct use of a term. The concomitant mental processes that may occur in the mind - the innumerous "techniques, not all of them necessarily conscious, people do use in pinning words to the world" (KUHN, 1983, p. 50, n. 22) - are irrelevant to determining if a person knows a word (HOYNINGEN-HUENE, 1993, 
p. 111). ${ }^{19}$ As Wittgenstein asserts $(2009, \$ 154)$, “comprehension is not a mental process". What matters is the ability to use the concept and to give explanations of such use in accordance with social standards.

Likewise, Kuhn argues that the criteria that make it possible for someone to use a concept are almost always irrelevant to its meaning (KUHN, 1983, p. 55; 1989, p. 63; 1991b, p. 219; 1993a, p. 231). Effective communication only requires that the members of the same language community "refer to the same objects and situations, not that they have the same expectations about them" (KUHN, 1993a, p. 239; 1993b, p. xiii). People can use whatever means they have to identify a referent, anything they know or judge about that natural kind. If the term is used in the same way by people, then it has the same meaning for them.

Kuhn restates this idea by saying that members of the same linguistic community do not need to share a lexicon - understood here as a set of criteria for selecting the referents of a contrast set. They only need to divide a lexical structure (KUHN, 1993a, p. 242), or "mutually congruent lexicons" (KUHN, 1991a, p. 104). People do not have to identify the objects in the same way; they only need to share the same "taxonomic categories of the world and the similarity/dissimilarity relationships between them" (KUHN, 1983 , p. 52). The meaning of a term, thus, depends solely on the homology of lexical structures (KUHN, 1993a, p. 231, n. 9), not on "the varied featurespaces within which individuals represent that structure” (KUHN, 1989, p. 77 , n. 25).

How is it possible, though, that individuals apply their own particular criteria for the establishment of a term, and are still able to select the same referents? Kuhn makes three remarks on this. First, he claims that there is a limit in the divergence among criteria used by scientists: "only a limited variety of expectations may be accommodated within a single speech community" (KUHN, 1993a, p. 231).

Secondly, homogeneity in educational and professional training - the fact that the same or similar examples and explanations tend to be given reduces the probability that teaching ends up producing very divergent expectations, because the social and natural world that speakers are exposed to during their socialization "does not present the sorts of objects and

\footnotetext{
${ }^{19}$ Mental states can be used as secondary criteria, as signs that suggest the speaker is likely to use a term properly. See Wittgenstein’s remarks on “learning on a stroke” (2009, \$185ff.).
} 
situations that would, by exploiting their criterial differences, lead them to make different identifications (KUHN, 1983, p. 51).” This is especially true of science, which possess "a rigorous and narrow education, probably more than any other, with the possible exception of theology" (KUHN, 1962, p. 165). ${ }^{20}$ Thus, homogeneity in teaching reduces the probability that very divergent expectations be produced.

Finally, Kuhn points out that the continuous interaction among scientists enables them to learn each other's criteria for selecting referents. With time, then, it is likely that "the congruence of their bodies of expectations will increase” (KUHN, 1993a, p. 239).

There is one last point to be considered. As discussed before, people can usually select the same referents by using different criteria and without changing the meaning of a term by doing so. There are some situations, however, when the subjective criteria employed by individuals can have an impact on the selection of referents, and therefore, on the meaning of a term. According to Kuhn, "while the world behaves in anticipated ways the ones for which the lexicon evolved - these differences between individual speakers make little or no difference" (KUHN, 1989, p. 73). Nonetheless, the appearance of new, unpredictable objects that violate the no-overlap principle - of "a dog that's also a cat (or, more realistically, a creature like the duckbilled platypus)" (KUHN, 1991a, p. 92) - can lead to divergences in the applications of terms, by virtue of the differences in the generalizations that were used to find the referents. Speakers, consequently, will be led to attribute distinct meanings to the same term.

\section{TruTh}

Taxonomies are important because they are one of the indispensable elements for producing meaningful statements (KUHN, 1991a, p. 92-93, 1981 , p. 30), together with the rules for formation of statements - what Kuhn calls "minimal laws of logic," and includes primarily the law of noncontradiction (KUHN, 1991a, p. 99).

The application of formation rules to a taxonomy is what enables the elaboration of an infinite number of statements. Particularly important among ${ }^{20}$ The importance of pedagogy for scientific research was present since Kuhn's early writings (see, for
example, 1959, p. 227) On the role of pedagogy in Kuhn, see (WARWICK; KAISER, 2005). 
them are the bipolar statements, those to which truth or falsity can be assigned (KUHN, 1991a, p. 99-100). Such statements are the candidates for scientific generalizations. It is the function of the researcher to pick those that seem of some interest and apply to them normal procedures of acceptance. These "standard techniques," Kuhn assures, "lead to some of these being accepted as true, others rejected as false" (KUHN, 1991a, p. 93).

The statements that can be elaborated from a given taxonomy are infinite; however, they do not represent their totality. A lexicon gives access to various sets of possible descriptions, but also prevents access to others (possible worlds, Kuhn states, are only possible in relation to a given lexicon). Furthermore, a lexicon does not determine what actually occurs in the world. It simply delimits what can be meaningfully said, restricting the set of conceivable beliefs. As Kuhn puts it, the lexicon determines "effability, not truth" (KUHN, 1993a, p. 249; 1999, p. 34-35). This is similar to the idea, better known in philosophy, of a "conceptual scheme," except for the fact that it does not refer to a specific set of beliefs accepted as true - a description of the world - but only to "the set of beliefs it is possible to conceive" (KUHN, 1991a, p. 94).

Kuhn adopts a redundancy or deflationary theory of truth. For him, it is only when a lexicon is assumed that the question of the truth or falsity of a statement has any meaning (KUHN, 1989, p. 77). The essential function of the concept of truth is "to require choice between acceptance and rejection of a statement or theory in the face of evidence by all" (KUHN, 1991a, p. 99). Truth, in other words, is no more than "a counter in a language game whose rules forbid asserting both a statement and its contrary" (KUHN, 1991a, p. 100).

In this sense, one can speak of the acceptance of scientific statements without saying that they are in themselves true or false. Instead, the assessment of sentences can be divided into two separate parts. First, it is necessary to check if it can be formed from the taxonomy and the formation rules accepted by the community. Next, assuming the answer to the previous question to be affirmative, it is necessary to apply the "normal rules of evidence" in order to establish whether the statement can be "rationally assertable" (KUHN, 1991a, p. 99).

On the other hand, it is not possible to say that the lexicon is true or false. Taxonomies are not in themselves true or false, nor do they represent an organization of the world independent of our language (KUHN, 1991a, p. 
104; 1993a, p. 244). Kuhn also denies that there is any sense in speaking of propositions as being true regardless of a taxonomy. For him, "truth" has only an intra-theoretical application (KUHN, 1970b, p. 162) - that of requiring a "choice between acceptance and rejection of a statement or a theory in the face of evidence shared by all” (KUHN, 1991a, p. 99). ${ }^{21}$

An extensive analysis of Kuhn's anti-realism would go far beyond the limits and purpose of this article. ${ }^{22}$ Nonetheless, it is interesting to note a few things. First, Kuhn repeatedly rejects the correspondence theory of truth - the notion that the truth or falsity of statements is established by their correspondence "to an external, mind-independent world" (KUHN, 1991a, p. 95). Second, despite constantly denying the correspondence theory of truth, his arguments vary a lot throughout his writings. Kuhn speaks, for example, of the absence of a definitive trend in the ontologies of theories over time (KUHN, 1970c, p. 205); that we only have access to sensations, and never to stimuli (KUHN, 1974); and that the notion of "truth" outside a given lexicon "has a vaguely ungrammatical ring" (KUHN, 1991a, p. 115).

Kuhn considers realism as strictly connected to the correspondence theory of truth, and that the redundancy theory of truth implies an anti-realist position, by posing a threat to the notion that "successive scientific beliefs become more and more probable or better and better approximations to the truth" (KUHN, 1993a, p. 243; 1991a, p. 95ff.). The idea that a deflationist semantics implies an anti-realist view of science is not obvious, though, nor unanimously accepted (FIELD, 1994, for example, is a realist who endorses a deflationary semantics). Unfortunately, nowhere does Kuhn justify this association.

Finally, Kuhn's rejection of the correspondence theory of truth can be seen as the main source of his evolutionary view on scientific development. There is no ultimate reality for theories to represent. Instead, what we have is a succession of more and adapted tools conceived by scientists to deal with the empirical world - a niche that evolves together with the practitioners (WRAY, 2011; KUUKKANEN, 2012).

\footnotetext{
${ }^{21}$ Already in SSR, Kuhn (1962, p. 169) sought to avoid the notion of "truth".

${ }^{22}$ Hoyningen-Huene (1993) and Sharrock \& Read (2002) offer very influential interpretations of Kuhn's anti-realist theses (the first on a Kantian framework and the second on a Wittgensteinian one).
} 


\section{Normic and Nomic Generalizations}

In one of his last papers, Kuhn (1993a) examines a second type of kind terms. He notes that terms like "force" or "electric charge" seem to possess a slightly different behavior than concepts learned through contrast sets, which form the most populous part of the lexicon (KUHN, 1993a, p. 239). ${ }^{23}$ Concepts of this second type are not learned simultaneously in contrast sets (KUHN, 1993a, p. 231). Instead, they are "learned from situations in which they occur together, situations exemplifying laws of nature" (KUHN, 1993a, p. $231 ; 1983$, p. 211). Much more than ostension, laws and theories play a fundamental role in establishing the reference of these terms (KUHN, 1979, p. 200). ${ }^{24}$

Kuhn calls these terms nomics, in opposition to normics, the concepts learned through contrast sets (KUHN, 1993a, p. 230). His only extended example of the learning of nomic terms is that of the vocabulary of Newtonian mechanics. For example, a teacher may initially convey the meaning of the term "force" with the help of a spring scale. Then, she may introduce Newton's second law, showing how for any body, acceleration is proportional to force. After that, the concept of "mass" is defined with the help of the second law as the variable inversely proportional to acceleration given a certain force. Finally, centripetal force devices provide an efficient way of measuring this mass. From there on, new empirical laws can be discovered, such as the law of universal gravitation, and concepts like "weight" can be defined and observed in physical situations (KUHN, 1989, p. 69ff.).

The first thing to note is that the teaching of some concepts is dependent on others. "Mass," for example, can only be defined after "force" and "acceleration." What is even more interesting is that "mass" is inherently

\footnotetext{
${ }^{23}$ Hoyningen-Huene (1993, p. 93) analyzes a similar distinction in Kuhn's (1979, p. 200) between terms learned by direct ostension and terms in which laws and theories contribute to the establishment of reference. My impression, however, is that Kuhn's remarks about "terms that are ordinarily applied by direct inspection," as a "game," and concepts in which "laws and theories also enter into the establishment of reference," as "electric charge," aim only at emphasizing the role of contrast sets for learning - more pronounced in the first case - and not at differentiating between types of concepts. Nersessian (2003, p. 183), in turn, believes that the distinction between taxonomic and non-taxonomic terms was already found in the SSR, in the distinction between basic and theoretical concepts. I believe this statement is even harder to sustain. In any case, even if a distinction between types of concepts had been intuited by Kuhn that early, it was only fully articulated later (1993a).

${ }^{24}$ Kuhn (1970c, p. 182) already recognized that symbolic generalizations do not merely play the role of laws of nature, functioning instead "in part as laws but also in part as definitions of some of the symbols they deploy".
} 
linked to a law of nature - in this case, Newton's second law. Although "force" and "acceleration" are defined independently of the second law, "mass" is defined simultaneously and through it, in a way that makes the law always valid, without admitting exceptions. If Newton's second law is true, then "mass" must be the ratio between "force" and "acceleration." Similarly, if "mass" is the ratio between "force" and "acceleration," then Newton's second law must be true. As for concepts learned by contrast sets, in nomic terms "nature and words are learned together" (KUHN, 1970c, p. 190). The difference now is that there is an "inextricable mixture of law and definition" in the establishment of these concepts (KUHN, 1964, p. 258).

Furthermore, the way a term is taught determines the epistemic status of some of the generalizations in which it appears. If "mass" had been described initially as an independent notion, and the law of gravitation had been presented as a stipulated law, Newton's second law could be introduced as a simple empirical generalization. Distinct learning routes "differ in what must be stipulated about nature," as well as in "what can be left instead for empirical discovery" (KUHN, 1989, p. 71). ${ }^{25}$

In reality, however, there is no single way in which theoretical terms are learned, and several kinds of learning styles or methods may take part in scientist's training (KUHN, 1989, p. 71-72). It becomes impossible, therefore, to say exactly which laws play a constitutive role in the meaning of a term and which of them have an empirical character (KUUKKANEN, 2008, p. 92).

In normal situations, in which the world behaves as expected, such divergences regarding the epistemic status of generalizations are of almost no relevance. Scientists can select the same referents, and "agree about the laws and other generalizations governing these objects and situations" (KUHN, 1989, p. 73). Even small changes in some of the laws could have a null effect on the meaning of the terms, since "other examples will maintain the lexicon stable, keeping in place a set of quasi-necessities equivalent to those initially induced by language learning" (KUHN, 1989, p. 72; WITTGENSTEIN, 2009, \$79). ${ }^{26}$

${ }^{25}$ Bird (2000, p. 174) interprets Kuhn's position as a thick intensionalism: the whole content of the theory is involved in the constitution of the meaning of a theoretical term. This is not Kuhn's view, though, since he insists that some statements are empirical in character - i.e., they do not contribute to the word's meaning.

${ }^{26}$ For Kuhn, there are no clear criteria that indicate at which point two scientists fail to assign the same meaning to a term. This poses a problem for the incommensurability thesis. If it is not clear which generalizations are constitutive of a word's meaning, then there is no rigid criterion to identify 
Nonetheless, these learning routes may sometimes have important implications for scientific practice. ${ }^{27}$ When scientists are confronted with resistant anomalies, such as considerable discrepancies between theory and observation, the nature of the accepted terms and generalizations may restrict the range of solutions that can be attempted (KUHN, 1974, p. 304, n. 14). ${ }^{28}$ For instance, scientists who learned "mass" through the first mode - and for whom the second law is a necessity that follows from the meaning of that term - would be free to change other empirical laws, while being constrained to preserve the second law. On the other hand, scientists who learned the term through a different path - for example, with the universal law of gravitation being stipulated and the second law as an observational consequence - would be obligated to keep the former, while at the same time free to change the latter. The difference in the "epistemic status of generalizations that community members share" (KUHN, 1989, p. 73) - the fact that they are treated as definitions or as mere empirical generalizations (a result of different paths to learning) - may lead to relevant differences of opinion when anomalies arise. ${ }^{29}$

Kuhn expressed some uneasiness in defining the nature of these stipulated laws. In a sense, they have a necessary character, and are not subject to refutation within a taxonomy - accepting a law is concomitantly accepting the terms it helps to define (and vice versa). It is not possible, for example, to adopt the term "mass" and at the same time reject Newton's second law, given that "no substitute for the second law is compatible with Newtonian language" (KUHN, 1983, p. 212). If the law fails, this means that the terms it implicitly defines have no reference. As Kuhn explains, these laws are "built into the lexicon" (KUHN, 1989, p. 71): "one can use the relevant parts of the language unproblematically only so long as one is committed to the law" (KUHN, 1983, p. 212). ${ }^{30}$

incommensurability between nomic terms, as there was one for normic ones (the difference in taxonomic structure).

${ }^{27}$ Kuhn (1964) brings interesting examples of how, in unforeseen situations, different situations can lead to conflicting and even contradictory applications of concepts. Mental experiments explore precisely this gap.

${ }^{28}$ For an interesting, early sketch of this position, see 1970c, p. 182ff.

${ }^{29}$ For an example related to Ohm's Law, see 1970c, p. 183.

${ }^{30}$ In SSR, Kuhn already noticed that Newton's second law seemed to behave "very much like a purely logical statement that no amount of observation could refute" (1962, p. 78). He said the same about the status chemical law of fixed proportion after Dalton (1962, p. 79-80). 
However, if we call these stipulated laws necessary, "necessity" here cannot have the meaning of "analyticity." After all, "experience with nature was essential to their initial formulation" (KUHN, 1989, p. 71; 1983, p. 212). But, according to Kuhn's own description, is not Newton's second law true precisely by virtue of the meaning of the terms "acceleration," "mass" and "force"? Yes. But there is a considerable difference in relation to a truly analytical or tautological sentence. The latter is true by virtue of the definitions of the terms it employs. For example, if I know what "married" and "single" means, then I know that the sentence "No single man is married" is necessarily true. In the case of Newtonian taxonomy, though, terms are not "independently available for use in a definition of the other" (KUHN, 1983, p. 212). In order to know the meaning of at least one of these concepts - in our case, "mass" it is also indispensable to know a natural law - in the case, - since both the second law and the term "mass" are defined together. And these laws, in turn, are not logical propositions. Instead, they make relevant statements about the behavior of the empirical world - statements that can always be tested and, in many cases, fail (KUHN, 1983, p. 212).

That is why a law of nature is not analytic: its necessity does not derive from the definition of independent terms, but is intertwined with some concepts that are defined concomitantly with it through stipulative generalizations (KUHN, 1989, p. 73, n. 19). For all this, Kuhn sees that these natural laws are closer to the Kantian idea of synthetic a priori: "synthetic," because they cannot "exist in the absence of experience"; and a priori, because "their experiential and their definitional content are inseparably merged" (KUHN, 1999, p. 36). ${ }^{31}$

Finally, we can consider the role of similarity relations in the learning of the nomic terms. When properly considered, natural laws are more properly "a law-sketch or a law-schema" (KUHN, 1970c, p. 188). Thus, the effective learning of a natural law is not limited to memorizing a formula. In order to become a competent member of the community, a student must learn to apply the law to a whole range of similar situations. That is exactly the function of the exercises at the end of textbooks; they help students to perceive "a way to see his problem as like a problem he has already encountered” (KUHN, 1970c,

${ }^{31}$ In some texts, Kuhn defines his position as a post-Darwinian Kantianism. The lexicon resembles Kant's a priori, in that "both are constitutive of possible experience of the world, but neither dictates what that experience must be" (1993a, p. 245). The difference between the Kantian a priori and Kuhn's lexicons is that "the lexical categories, unlike their Kantian forebears, can and do change, both with time and with the passage from one community to another" (1991a, p. 104). 
p. 188; 1970c, p. 188). Nomic terms, therefore, also require the presentation of similar objects. The difference is only "between the level at which similarity enters" (ANDERSEN et al., 2006, p. 32). While in the normic terms the similarity classes comprises instances of the contrasting kinds, in nomic terms the similarity classes are constituted by problem-situations.

As in the case of contrasting concepts, the ability to use a nomic term adequately is what determines that someone understands it. However, the skill in this case involves more than just the capacity of identifying the referent in a contrast set. Understanding a nomic term demands knowing a symbolic generalization and being able to use the appropriate form of the law in a family of "complex problem situations to which a given law applies and which involve the simultaneous use of several concepts" (ANDERSEN; NERSESSIAN, 2000, S229).

\section{Conclusion}

The philosophy of language that we have discussed throughout this article is the result of Kuhn's intense enquiries, especially those conducted in his later articles, written between the 1980s and 1990s. The basis of this philosophy is a theory about the nature of concepts, which stems from considerations on learning techniques. The analysis of these processes illuminates how terms for species are family resemblance concepts, which requires that they be learned simultaneously, within a set of contrasting concepts. These networks of related concepts are called "taxonomies" or "lexicons."

Next, two topics related to this theory of concepts were discussed. In the first place, a theory, although only briefly sketched in Kuhn's texts, of meaning. The meaning of a term is understood as its usage, which implies knowing its relations with other terms in the taxonomy, as well as the objects of the world to which it refers. The second theme was a deflationary theory of truth. For Kuhn, the bipolarity of a statement - the fact that it can assume the values "true" or "false" - indicates only its legitimate construction according to the taxonomy and syntactic construction rules accepted by the community. Additionally, to consider a certain statement as true is only to affirm that, besides being a possible statement within the language, it was in accordance with the social procedures for the acceptance of statements. 
Finally, a second class of concepts (unfortunately, not much studied by Kuhn), not acquired by means of contrast sets, was indicated. These terms, such as "mass" and "force," are learned from generalizations, and their meaning is intertwined with the laws used to define them. Consequently, it is not possible to change such laws without, at the same time, rejecting the taxonomy itself.

Kuhn's intention in elaborating a philosophy of language was mainly that of clarifying two central themes that run through his work since SSR: revolutionary change and incommensurability. ${ }^{32}$ Both are reworked from an eminently semantic perspective. Scientific revolutions are now seen as changes that require the substitution of a taxonomy, while incommensurability is redefined as the impossibility of translating statements constructed within one taxonomy into those from another. The conception of language developed by Kuhn that we have presented in this article is the basis for these late re-elaborations of his main philosophical theses. Most importantly, this philosophy of language can be of interest per se for its reappraisal of classical themes in philosophy of language, such as "meaning" and "truth."

PIROZELLI, P. A filosofia da linguagem de Thomas Kuhn. Trans/form/ação, Marília, v. 43, p. 345-372, 2020. Ediçâo Especial.

Resumo: Thomas Kuhn é conhecido principalmente por suas contribuiçōes para a filosofia da ciência. No entanto, foi em grande medida à filosofia da linguagem que ele dedicou a última parte de sua carreira. O objetivo deste artigo é apresentar uma visão sistemática das principais ideias de Kuhn sobre esse assunto. Começo descrevendo sua teoria do conceito, em particular o que ele diz sobre termos para espécie (kind terms). Tais termos, aprendidos em blocos que formam conjuntos de contraste ou "taxonomias", são aprendidos através de definições ostensivas. Em seguida, analiso as concepçóes de Kuhn de "significado" e "verdade". Finalmente, discuto um segundo tipo de termo para espécies, não totalmente investigado por ele, que é aprendido junto com as leis científicas.

Palavras-chave: Thomas Kuhn. Filosofia da Linguagem. Taxonomia. Significado. Verdade.

${ }^{32}$ Virtually all articles written by Kuhn from the 1980s onwards deal somewhat with semantic incommensurability and revolutionary change. For more detailed discussions on these themes, see CHEN, 1997; SANKEY, 1993; HOYNINGEN-HUENE, 1990; D’AGOSTINO, 2014; MARCUM, 2015; and the articles in MIZRAHI, 2018. 


\section{REFERENCES}

ANDERSEN, H. Kuhn's account of family resemblance. Erkenntnis, v. 52, p. 313-37, 2000.

ANDERSEN, H.; NERSESSIAN, N. Nomic Concepts, Frames, and Conceptual Change. Philosophy of Science. v. 67, S224-S241, 2000.

ANDERSEN, H.; BARKER, P.; CHEN, X. The Cognitive Structure of Scientific Revolutions. Cambridge: Cambridge University Press, 2006.

BAKER, G. P.; HACKER, P. M. S. Wittgenstein: Understanding and Meaning. Part 1: Essays. Oxford/Cambridge, MA: Blackwell, 2009.

BARKER, P.; CHEN, X.; ANDERSEN, H. Kuhn on Concepts and Categorization. In: NICKLES, T. (Ed.). Thomas Kuhn. Cambridge: Chicago University Press, 2003.

BIRD, A. Thomas Kuhn. Princeton: Princeton University Press, 2000.

CHEN, X. Thomas Kuhn's Latest Notion of Incommensurability. Journal for General Philosophy of Science, v. 28, p. 257-73, 1997.

D’AGOSTINO, Fred. Verballed? Incommensurability 50 years on. Synthese, v. 191, n. 3, p. 1-22, 2014.

FIELD, H. Deflationist views of meaning and content. Mind, v. 103, n. 411, p. 249285, 1994.

HACKING, I. Language, Truth and Reason. In: HOLLIS, M; LUKES, S. (Eds.). Rationality and Relativism. Cambridge, Ma: MIT Press, 1982, p. 49-66.

HACKING, I. Working in a New World: The Taxonomic Solution. In: HORWIVH, P. (Ed.). World Changes: Thomas Kuhn and the Nature of Science. Pittsburgh: University of Pittsburgh Press, 1993.

HOYNINGEN-HUENE, P. Kuhn's conception of incommensurability. Studies in History and Philosophy of Science, v. 21, n. 3, p. 481-492, 1990.

HOYNINGEN-HUENE, P. Reconstructing Scientific Revolutions: Thomas Kuhn's Philosophy of Science. Chicago: Chicago University Press, 1993.

KHALIDI, M. A. Natural Kinds and Crosscutting Categories. The Journal of Philosophy, v. 95, n. 1, p. 33-50, 1998.

KUHN, T. S. The Essential Tension. In: The Essential Tension. Chicago: Chicago University Press, 1977 (1959).

KUHN, T. S. The Structure of Scientific Revolutions. Chicago: Chicago University Press, 2012 (1962).

KUHN, T. S. A Function for Thought Experiments. In: The Essential Tension. Chicago: Chicago University Press, 1977 (1964). 
KUHN, T. S. Logic of Discovery or Psychology of Research. In: KUHN, T. S. The Essential Tension. Chicago: Chicago University Press, 1977 (1970a).

KUHN, T. S. Reflections on my Critics. In: KUHN, T. S. The Road since Structure. Chicago: Chicago University Press, 2000 (1970b).

KUHN, T. S. Postscript. In: KUHN, T. S. The Structure of Scientific Revolutions. Chicago: Chicago University Press, 2012 (1970c).

KUHN, T. S. Second Thoughts on Paradigms. In: KUHN, T. S. The Essential Tension. Chicago: Chicago University Press, 1977 (1974).

KUHN, T. S. Metaphor in Science. In: KUHN, T. S. The Road since Structure. Chicago: Chicago University Press, 2000, (1979).

KUHN, T. S. What are Scientific Revolutions? In: KUHN, T. S. The Road since Structure. Chicago: Chicago University Press, 2000 (1981).

KUHN, T. S. Commensurability, Comparability, Communicability. In: KUHN, T. S. The Road since Structure. Chicago: Chicago University Press, 2000 (1983).

KUHN, T. S. Possible Worlds in History of Science. In: KUHN, T. S. The Road since Structure. Chicago: Chicago University Press, 2000 (1989).

KUHN, T. S. The Road since Structure. In: KUHN, T. S. The Road since Structure. Chicago: Chicago University Press, 2000 (1991a).

KUHN, T. S. The Natural and the Human Sciences In: KUHN, T. S. The Road since Structure. Chicago: Chicago University Press, 2000 (1991b).

KUHN, T. S. The Trouble with the Historical Philosophy of Science. In: KUHN, T. S. The Road since Structure. Chicago: Chicago University Press, 2000 (1992).

KUHN, T. S. Afterwords. In: 1992 The Road since Structure. Chicago: Chicago University Press, 2000 (1993a).

KUHN, T. S. Foreword. In: HOYNINGEN-HUENE, P. Reconstructing Scientific Revolutions: Thomas Kuhn's Philosophy of Science. Chicago: Chicago University Press, 1993 (1993b).

KUHN, T. S. Remarks on Incommensurability and Translation. In: FRAVETTI et al. (Eds.). Incommensurability and Translation. Cheltenham, UK and Norhampton, MA: Edward Elgar, 1999, p. 33-37.

KUUKKANEN, J-M. Meaning Change. Saarbrücken: VDM Verlag, 2008.

KUUKKANEN, J-M. Kuhn on Essentialism and the Causal Theory of Reference. Philosophy of Science, v. 77, p. 544-64, 2010.

KUUKKANEN, J-M. Revolution as Evolution: The Concept of Evolution in Kuhn's Philosophy. In: KINDI, V; ARABATZIS, T. (Eds.). Kuhn's The Structure of Scientific Revolutions Revisited. New York: Routledge, 2012. 
MARCUM, J. The Evolving Notion and Role of Kuhn's Incommensurability Thesis. In: DEVLIN, W. J; BOKULICH, A. (Eds.). Kuhn's Structure of Scientific Revolutions 50 Years On. Springer, 2015.

MCDONOUGH, J. K. A Rosa multiflora by Any Other Name: Taxonomic Incommensurability and Scientific Kinds. Synthese, v. 136 n. 3, p. 337-358, 2003.

MIZRAHI, Moti. The Kuhnian Image of Science: Time for a Decisive Transformation? London: Rowman \& Littlefield, 2018.

NERSESSIAN, N. Kuhn, Conceptual Change, and Cognitive Science. In: NICKLES, T. (Ed.). Thomas Kuhn. Cambridge: Chicago University Press, 2003.

NICKLES, Thomas. Normal Science: From Logic to Case-Based and Model-Based Reasoning. In: NICKLES, T. (Ed.). Thomas Kuhn. Cambridge: Chicago University Press, 2003.

SANKEY, Howard. Kuhn's Changing Concept of Incommensurability. The British Journal for the Philosophy of Science, v. 44, n. 4, p. 759-74, 1993.

SEARLE, John. Metaphor. In: ORTONY, A. (Ed.). Metaphor and Thought (2ed). Cambridge: Cambridge University Press, 1979.

SHAPERE, Dudley. The Structure of Scientific Revolutions. The Philosophical Review, v. 73, n. 3, p. 383-394, 1964.

SHARROCK, Wes; READ, Rupert. Kuhn: Philosopher of Scientific Revolution. Cambridge: Polity Press, 2002.

WARWICK, A.; KAISER, D. Kuhn, Foucault, and the Power of Pedagogy. In: KAISER, D. (Ed.). Pedagogy and the Practice of Science. Cambridge, MA: The MIT Press, 2005, p. 393-409.

WITTGENSTEIN, Ludwig. Philosophical Investigations. Basil: Wiley-Blackwell, 2009.

WRAY, Brad. Kuhn's Evolutionary Social Epistemology. Cambridge: Cambridge University Press, 2011.

Recebido: 26/11/2019

Aceito: $17 / 02 / 2020$ 
PIROZELLI, P. 